\title{
"LA PERFORMANCE MUESTRA UNA RAPACIDAD O UNA APROPIACIÓN SOBRE EL POEMA ESCRITO" ENTREVISTA A ROBERTO ECHAVARREN
}

\begin{abstract}
Irina Garbatzky. Ayudante de $1^{\circ}$ en la cátedra Literatura Iberoamericana II de la Universidad Nacional de Rosario y becaria doctoral de CONICET. Su tesis se titula: "Poesía y performance. Las prácticas poéticas en el Río de la Plata hacia fines de siglo XX".

E-mail: irinagarbatzky@gmail.com
\end{abstract}

Entrevisté a Roberto Echavarren en Abril de 2008 en Buenos Aires. En ese momento me interesaba charlar con este poeta, narrador y ensayista uruguayo, quien también ha transitado por el film, la instalación y la performance, respecto de sus reflexiones en torno a esta última cuestión, algunas conceptualizadas en su libro Fuera de género. Criaturas de la invención erótica (Buenos Aires, Losada, 2007).

A pesar de que han pasado tres años de dicho encuentro, las palabras de Echavarren aquí transcriptas condensan algunas perspectivas ciertamente contundentes respecto de los ejes performance, oralidad, poesía, lengua y territorio. Tal como en Arte andrógino, estilo versus moda (Buenos Aires, Colihue, 1998) y en otros artículos, prólogos y ensayos críticos, Echavarren busca des-construir y revertir los espejismos y las reducciones culturales. En este caso vinieron a su observación: la espectacularización de la performance, la idealización de la lectura en voz alta y el destierro de lo visual.

Dado que la poética de este autor se inscribió en una corriente de frontera, como lo es el neobarroco en el Río de la Plata; el posicionamiento y la autorreflexión respecto de estas nociones se vuelven sumamente significativos. Para Echavarren no se trata de priorizar una dimensión por sobre otra, o de construir una valoración de la poesía a partir de una puesta escénica, sino de subrayar dos instancias: una noción moderna de poesía, donde el poema acontece sobre el blanco de la página, y una práctica "rapaz", -así la llama él mismo en este lugar-, la performance, cuya potencia reside en el desmembramiento de una única voz en provecho de la multiplicidad de las voces o inclusive, de su silencio. Para Echavarren, la performance no necesariamente debe ser "poética", ni implicar la oralidad, sino que resulta una actividad abierta, amplia y diversificada.

Asimismo, en esta ocasión, Echavarren tiene la oportunidad de discernir entre la performance como disciplina y la declamación a partir del ejemplo de la poeta uruguaya Marosa Di Giorgio, anterior al autor en las fechas de sus primeras publicaciones, pero contemporánea en la periodización que Ángel Rama esbozara como la última promoción de la Generación Crítica. 
La otra revisión hecha en esta oportunidad, es la idea de una poesía nacional o local. Esta es una cuestión que condice con sus intereses respecto de lo global y que se sustenta en una particular formulación del territorio y de la historia a lo largo de su obra. En este sentido el pasaje entre lenguas y lenguajes, entre ciudades y culturas, en la poética de Echavarren, se vuelve correlativo, o bien, hallaría un punto de vista en el carácter transplatino que supusieron las escrituras neobarrocas, dispersas en distintos puntos del planeta. La pregunta por lo global trastoca, además, la dimensión política, supone una revisión de los paradigmas, tanto de la antigua izquierda como de los movimientos reivindicatorios de las minorías.

Desde nuestra charla en aquel café porteño, este prolífico escritor publicó, entre otros, los poemas reunidos en El expreso entre el sueño y la vigilia (Montevideo, Fundación Nancy Bacelo, 2009), la novela Yo era una brasa (Montevideo, Hum, 2009) y los relatos de La salud de los enfermos (Montevideo, Hum, 2010).

\section{¿Cómo son los pasajes entre poesía y performance?}

Es muy problemático articular poesía y performance. ¿Por qué? Hay una cierta tradición en la poesía, que la poesía deja de ser oral para transformarse en algo escrito, en un libro. Y esa noción de que la poesía dejó de ser algo cantado, por un trovador o lo que fuera, uno debe verla en la página; y ahí, por ejemplo, encontraremos a Mallarmé con los espaciamientos de la página, o la poesía concreta brasilera. Es un asunto del ver y se emparienta con la obra plástica. Yo creo que la poesía en el sentido moderno contemporáneo es algo que está en la página y es algo silencioso, porque ya nosotros no leemos moviendo los labios como hace cinco siglos ni necesitamos leer en voz alta como se hacía en las tertulias del siglo XIX. La poesía es un asunto silencioso de la página. Nosotros nos acostumbramos paulatinamente a captar el ritmo del poema a través de una lectura silenciosa donde nada suena. Es como una construcción mental. Están implícitos y evocados los órganos de la fonación, la memoria motora, acentuación del sonido, el oído, pero todo está convertido en una especie virtual. Ahora bien, ¿la performance va a realizar el poema en un sentido pleno, en un sentido que es a la vez oral y sensible y performático, o no? Yo creo que normalmente lo que sucede es que la performance desfigura el poema completamente. La gente grita o dice una palabra de una manera y después dice otra en otro tono, o lo que fuera. $\mathrm{Y}$ entonces el poema como secuencia en la página es una cosa y otra cosa es la performance, que de repente puede retomar una palabra del poema, pero básicamente lo chorretea, lo deforma, lo deshace.

\section{Habría un abismo similar entre Marosa Di Giorgio y sus lecturas, ¿no es cierto?}


El problema ahí es otro problema, que no es sólo el de la performance: de qué manera la lectura hecha por el propio poeta hace alteridad en relación al poema mismo. Porque si podemos concebir al poema como el liberarse de una identidad, o el modo en que un poema puede contener muchas voces o muchas maneras de decir, entonces el lector de la página silenciosa puede elegir entre esas voces, parece que el poeta al leerlo en voz alta está condicionando una cierta lectura del poema o una interpretación y en ese sentido creo que está restringiendo lo que dice el poema a una voz que tiende a ser una voz sumisa y una especie de ego. Mientras la poesía en la página puede ser el estallido del ego o de la identidad, la lectura en voz alta tiende a restituir ese ego o esa identidad. Y en ese sentido perdería todo el poder dispersivo del poema y su riqueza. Entonces es muy problemática la lectura en voz alta. Allí se encuentran nuestras entonaciones y nuestras idiosincrasias y todo lo que heredamos de la educación, lo que se nos ha inculcado. Es decir si habla un hombre no es una voz aguda, si es una mujer, no se va a transformar en un barítono... Siempre hay harapos de identidad que está incorporada. No es que sea una decisión voluntarista, sino que nos sale así porque es como una persona ante el mundo. A la vez, es otra dimensión.

\section{¿La escritura puede pensar una performance?}

No, yo no pienso en la performance cuando escribo. Cuando escribo es una voz secreta para mí mismo, y por lo tanto no la estoy integrando a toda a mi representación. Por eso me parece que la performance encuentra una rapacidad o una apropiación y una violencia sobre el poema escrito. No quiero decir con esto que estoy despreciando la performance o que la performance no me parezca legítima. Creo que es una dimensión propia, diferente. Creo también que hay una distancia entre la lectura en voz alta hecha por un poeta y lo que podemos considerar performance; porque la performance puede ser de una o varias personas, y además la performance no tiene por qué respetar el poema como la respetaría la lectura en voz alta, sino que es más bien una serie de variaciones posibles acerca de un pretexto que puede ser el poema. El poema puede quedar pulverizado y la performance puede existir por derecho propio. Yo creo que es eso, que son dos dimensiones autónomas. Ni la performance domina al poema ni el poema domina la performance. Creo que la lectura en voz alta nos puede orientar o hacernos más lúcidos en relación a la distancia. Porque en una lectura en voz alta entregamos todo nuestro "paquete" de performatividad de nuestra voz y nuestros gestos, y creo que el poema es otra cosa. Antes sería diferente, los trovadores provenzales cantaban y tocaban un instrumento. A mí me parece que siempre hay en el arte, más que el Gesamtkunstwerk, como decía Wagner, más bien caminos diferentes que se van abriendo cada vez más. Por ejemplo, entre los "Language poets", hay un "Archivo de la palabra", una obsesión por grabar y grabar. Y yo pienso, John Ashbery, por ejemplo, lee en un monótono. Esas dos líneas a partir de los '50, históricas, entre los beatniks, como Allen Ginsberg, que hablaban con su acordeón o su 
armónica y su idea del poema oral, y que fueron derrotados por el rock, cuando surgió, y lo que se llaman los "Poetas de Nueva York", de los que yo creo el más interesante es John Ashbery, más bien están versados en la idea del poema como algo en la página, como escritura y vinculado con la pintura. Frank O’Hara era crítico de pintura, Jasper Jons hacía obras plásticas con algunos poemas de Frank O’Hara, con algunos versos. Y cuando Ashbery lee un poema, lo lee en una especie de monótono. Como si la lectura oral fuera una especie de ocasión de escucha, pero que no es la ocasión decisiva donde se resuelve el impacto del poema, y esa misma lectura como un monótono parece sugerir eso. Ahora bien, a Marosa le interesaba mucho la declamación. Ella estudió declamación en Salto, cuando joven. Y creo que intervino en algunas obras de teatro. Bueno, estaba Berta Singerman. Yo la vi de niño a Berta Singerman en Punta del Este, toda llena de velos y de sedas, y con cada poema se cambiaba el velo... Pero era cursi. Pienso que Rubén Darío con "La marcha triunfal" dio paso a todas estas declamadoras, y después García Lorca. A pesar de su homosexualidad, que no se podía mencionar en su momento, es un poeta de lo oral y del teatro y de la declamación. Y Margarita Xirgu, que actuaba en las obras de Lorca, después en Montevideo fundó la Comedia Nacional.

\section{¿Entonces pensás que entre oralidad, poesía y performance no habría ninguna vinculación?}

Yo no estoy en contra de la oralidad, sino que me parece que es interesante hacer un deslinde siempre. En la performance habría mucho del poema, una versión, pero no necesariamente algo que haga autoridad, como si dijera hay que escuchar a Neruda diciendo "Y dónde están las lilas...!" Podés leer el poema y ver otras cosas y no tener que escuchar la voz empalagosa de Neruda. Esto nos trae un problema de poética realmente, es decir qué es lo que está involucrado en la escritura del poema; si es el poema una liberación de una identidad o es a la manera romántica hablar siempre del yo. El mismo Perlongher habla de esto en algún momento. La poesía neobarroca es una poesía del estallido de la identidad, de la proliferación, y eso es difícil de resumirlo en una voz. Además hay poetas que leen muy mal su poesía, no? Cuando yo empecé a leer poesía de adolescente, era silenciosa. Descubrí a Darío, a Bécquer, y siempre era lectura silenciosa. Nunca estuve muy aferrado a los intérpretes de poesía. Además me reventaba mucho el kitsch, ese "Y yo me la llevé al río...!", esa cosa exagerada. Generalmente los actores cuando leen poesía son un horror, porque ellos tienen que darle una interpretación como actuación y entonces es sobreactuado. La performance es un campo muy libre, puede ser cualquier cosa e incluso puede ser silenciosa. No necesariamente está asociada a la palabra o al poema. Es decir, habría que ver la performance desde varias vetas, porque es un campo infinito. 


\section{¿Se conecta la performance con lo que vos escribís en Arte andrógino sobre el rocker?}

Creo que lo del rocker era muy aventurado y novedoso en la época de Jim Morrison, porque él mismo no sabía qué iba a hacer, y estaba inspirado en el Living Theatre. Esto también aparece en Ave roc (novela, Buenos Aires, Mansalva, 2007). Pero me parece que más adelante, después, es algo más codificado un concierto de rock que lo que puede ser hoy el campo de la performance. El público es diferente, es menos popular. Es otra dimensión del espectáculo. Creo que los conciertos de rock se han vuelto más previsibles con el tiempo.

\section{¿Si la performance no tiene necesariamente que ver con lo poético, cómo entendés esto?}

Hay una performance genial y silenciosa que yo describo en el ensayo "Género y sexo" de una holandesa. Ella hacía movimientos y tocaba objetos, y no tenía nada que ver con la palabra.

\section{¿Cómo pensás la relación entre la performance y el registro?}

No se trata de un problema muy nuevo, porque si te ponés a pensar, ¿qué es el teatro? En el teatro vos ves una obra de Shakespeare o lo que sea, y después de que termina, pasa la temporada, ¿qué queda? Es un tipo de arte que se consume en el momento y se acabó. No hay mucho más misterio.

\section{¿Cómo era el panorama en Uruguay a finales de los años ochenta, durante la transición democrática?}

Lo que pasa es que yo en los setenta viví en Londres y después me fui a Nueva York. Creo que en ese momento había una diferencia radical entre lo que podía ser la vida en Buenos Aires o Montevideo y lo que podía ser la vida en Ámsterdam, en Nueva York. En Londres estuve vinculado al Gay Liberation Front. Y acá hubo también movimientos de liberación homosexuales, de que participó Perlongher, pero obviamente todo eso fue tragado por las fauces de los militares y la policía y todo aquello. Entonces a mí me parece que había un hiato enorme, y lo que veía en Uruguay era una antigua izquierda, leninista, castrista. Una izquierda cuyo único plan era apoderarse del poder central. En el '68 cuaja otra idea de izquierda que es la de Foucault o Deleuze. La idea de micropolítica, en donde alterar esas relaciones de poder es válido y no solamente en relación a un poder central, de gobierno, sino en torno a la familia, el trabajo, la calle. Esa idea de izquierda es la que a mí 
me interesa y me sigue interesando. La otra izquierda me parece horriblemente aburrida y además está ligada a la represión, porque cuando esa ideología llega al poder se transforma en una política represiva y machista, como en el caso de Cuba, con campos de concentración para homosexuales... No es salirse de la izquierda sino inventar otra izquierda. Yo viví la otra izquierda, porque por suerte pude irme, porque la viví en Amsterdam. Esa grieta se ha ido colmando con los años, y además ahora con internet no hay un centro donde comiencen las cosas: como el diseño, la música, la performance, el rock, la experiencia de las drogas o del comportamiento. Esto sucede en todas partes y en ninguna. Las reivindicaciones de género y de minorías (sean de raza, sean de preferencia sexual, sean de feminismo) se han vuelto globales y entonces el problema cambia de terreno. Porque lo que antes era una problemática dentro de los estados occidentales y cristianos, ahora es más bien un choque entre culturas diferentes. Por ejemplo tenemos a los grupos inmigratorios musulmanes en Europa, que toman actitudes muy violentas contra las minorías sexuales, las mujeres, con la historia del velo. En Holanda en 2002 mataron a un político gay porque él defendía ciertas actitudes liberales frente a la intolerancia musulmana. Es decir, la problemática es la misma pero lo que ha cambiado es el terreno de las confrontaciones. Entre un Occidente que muy precariamente ha llegado a ser más tolerante y un Oriente donde el libro sagrado es el Corán y es inflexible.

\section{Volviendo a la transición democrática, la movida de Buenos Aires de teatro, con personajes como Batato Barea (actor clown travesti del underground porteño), supuso una instancia de reunión y de contacto vincular. ¿Cómo fue eso en Uruguay?}

En Uruguay no hubo un Batato Barea... Pero, bueno, hubo una Marosa di Giorgio. Creo que el proceso de Uruguay es paralelo al Argentino. A veces las cosas no se sabe dónde se originan. Ahora si dos hombres se saludan, normalmente, se dan un beso. Antes eso era increíble, tenías que dar la mano de una manera viril. Hubo un pasaje de ablandamiento. Creo que otro factor importante fue el pelo largo. De repente los militares agarraban a los de pelo largo y los rapaban y ahora está todo bien. Creo que el cambio en Uruguay es paralelo en Argentina, de la sensibilidad, de las actitudes machistas que se van volviendo más suaves, aunque no desaparezcan.

\section{¿Tu poesía y la de Marosa son extrañas en el contexto rioplatense?}

Centralasia (poesía, Tsé Tsé, 2005) es un libro sobre el Tibet. Creo que los que empezaron a hablar sobre lugares lejanos y sobre culturas diferentes en la poesía latinoamericana fueron los modernistas. Rubén Darío hablaba de otros tiempos y de otros lugares, Herrera y Reissig, el poeta uruguayo, tiene unos sonetos vascos, Julián del Casal, en Cuba, habla de la nieve y de la cubana japonesa... Después vino otra corriente más 
latinoamericanista que juzgaba a los modernistas de exóticos, diciendo que tendrían que hablar de nuestros problemas o de lo local en lugar de la India. Eso que parecía exótico en ese momento, ahora no parecería exótico porque nadie se extraña de que alguien esté preocupado por los problemas globales ya sea calentamiento o la guerra de Irak o las mujeres musulmanas o el asesinato a los homosexuales en Irán. Yo creo que hay una sensibilidad global donde ya no se acusa más de ser exótico. Lo local viene por otro lado. El habla es local, hay distintos españoles: en Chile, en Perú, en Venezuela. Lo local es irreductible y tiene que ver con actitudes vividas y con el habla en cada lugar. Lo local también es el modo de vida y la tradición cultural. Por ejemplo en Indonesia, la sociedad está basada con la magia y el animismo. La sociedad brasilera está relacionada con la religión de los orixás. Eso no se nota desde afuera, pero se filtra. Yo escribí un libro sobre el Tibet: China invadió Tíbet en 1959 y aplastó una cultura, una tradición religiosa, etcétera, y ahora como antes resurge la rebelióndel Tíbet. $\mathrm{Y}$ en cada lugar donde se transporta la antorcha olímpica hay demostraciones de solidaridad con el Tíbet. Eso sucedió en Atenas, en París, en Londres, en San Francisco. Quiere decir que el problema del Tíbet, que para la época de los modernistas podría parecer exótico, es un problema global y nos concierne a todos. Si alguien en el Golden Bridge cuelga una pancarta que dice "free Tibet" implica que hay un conflicto global, que hay una globalización de los problemas. Mi libro, que podía parecer gratuito: ¿por qué un tipo de Montevideo escribe sobre el Tíbet? Justamente, porque tengo una preocupación global y además porque trato de repensar el budismo a través de una cultura como la de Tíbet. Centralasia habla de la guerra con China y de los episodios marginales que continúan hostigándose. Mi escritura es parte de esa conciencia global.

\section{¿Cómo son los vínculos entre la lengua materna y la lengua extranjera? Esa idea de lo extraterritorial, de que cada poeta se encuentra en dislocación con la lengua en la que le toca nacer...}

Eso sería lo local. Yo viví casi 20 años en Nueva York y sin embargo, por más que soy completamente bilingüe, porque puedo leer un libro lo mismo en inglés que en español, no tuve la infancia en E.E.U.U. ni la escuela primaria ni la escuela secundaria y entonces hay una cantidad de cosas que resultan inasibles, porque no las ha vivido, para alguien que vino después, a enseñar en la universidad. Hay algo que se me va a escapar siempre de ese local, del inglés. Es algo irreductible. 